\title{
Impacts of PU Foam Stand-Off Layer on the Vibration Damping Performance of Stand-Off Free Layer Damping Cantilever Beams
}

\author{
Longqiang Liang $\left(\mathbb{D}\right.$, Weibo Huang $\mathbb{D}^{\mathbb{D}}$, Ping Lyu $\mathbb{D}^{\mathbb{D}}$, Mingliang Ma, \\ Fandi Meng, and Yingjie Sang \\ School of Civil Engineering, Qingdao University of Technology, Qingdao 266033, China \\ Correspondence should be addressed to Weibo Huang; huangweibo@qut.edu.cn and Ping Lyu; lyuping_qut@sina.com
}

Received 7 May 2020; Revised 23 September 2020; Accepted 29 October 2020; Published 17 November 2020

Academic Editor: Hassan Haddadpour

Copyright (c) 2020 Longqiang Liang et al. This is an open access article distributed under the Creative Commons Attribution License, which permits unrestricted use, distribution, and reproduction in any medium, provided the original work is properly cited.

\begin{abstract}
Stand-off free layer damping is a vibration reduction method based on the traditional free layer damping. In this paper, a stand-off free layer damping cantilever beam is prepared with the steel plate as the base layer, rigid polyurethane (PU) foam as the stand-off layer, and rubber as the damping layer, and the motion equation of the cantilever beam is derived. The dynamic mechanical properties of damping rubber and PU foam are tested and analyzed. Through hammering tests, we have studied the effect of the density and thickness of the PU foam layer on the amplitude-frequency curves, modal frequencies, and loss factors of the cantilever beams. The results show that the rubber damping material is a major font of energy dissipation of the cantilever beam, and PU foam acts mainly to expand the deformation of the damping layer and plays a role in energy consumption. By increasing the density and thickness of PU foam within a certain range, the vibration peaks of the first five modes of the cantilever beam decreases gradually, the loss factors rise, and the damping performance is improved. Meanwhile, increased density and thickness enhances the overall stiffness of the beam, making the modal frequencies get higher.
\end{abstract}

\section{Introduction}

The vibration and noise generated during the navigation of a ship not only seriously affects the comfort of the ride but also affects the rest of the crew. It will also reduce the technical performance of the ship, causing fatigue damage to the mechanical structure and abnormal instrumentation. Due to the special requirements of the production and development of the ship manufacturing industry, trying to reduce the vibration and noise of the ship is a focus of research [1,2]. There are generally two technical measures to reduce vibration and noise: one is to try to reduce the intensity of the noise source itself and the other is to use damping and absorbing materials to dissipate the vibration and noise energy. The use of damping materials to control vibration and noise is more convenient to implement, and it is a commonly used means of vibration and noise reduction $[3,4]$.

Damping materials on ships often exist in two structural forms: free layer damping structure and constrained layer damping structure [5, 6]. In 1959, Yellin et al. [7] first proposed adding a stand-off layer between the base layer and the damping layer to expand the energy dissipation deformation of the damping layer and to improve the vibration damping performance. By introducing a stand-off layer into the traditional damping structure, a stand-off structure can be formed, including stand-off free layer damping and constrained layer damping. An ideal stand-off layer has a bending stiffness close to zero, a shear stiffness approaching infinity, and incompressibility [8]. Stand-off constrained layer damping is an efficient damping treatment, which has been studied extensively and deeply. Yellin et al. [9, 10], based on the Euler-Bernoulli beam, analyzed the frequency response of the stand-off damping and compared it with the traditional constrained layer damping. The results show that the standoff layer can significantly increase the energy dissipation level of the damping layer. Research by Yan et al. [11-13] showed that when the elastic modulus of the stand-off layer is 100 times that of the damping layer, the tube-shaped stand-off 
damping model can achieve better vibration reduction performance without changing the natural frequency of the structure. Kumar [14] claimed that increasing the thickness and modulus of the constrained layer can improve the damping performance. Yi et al. $[15,16]$ demonstrated that the particle swarm optimization algorithm can better solve the dynamic optimization problem of stand-off damping structures by using the cosimulation method of ANSYS and MATLAB. Garrison et al. [17-19] conducted a targeted analysis of the constrained damping with the local stand-off layer and believed that the locally stand-off damping treatment has a higher damping efficiency though the damping area is reduced. They made optimal design of its vibration damping performance. Rao [20] pointed out that the slotted stand-off layer reduces the bending stiffness and overall mass of the structure and thus can effectively control the vibration and noise in aircraft cabins. Meng [21] showed that the introduction of the slotted stand-off layer is very helpful in improving the damping effect of the structure. Zhao et al. [22-24] discovered, through numerical simulations and experimental tests, that the noise of constrained mute rails with slotted stand-off is reduced by more than $6-9 \mathrm{~dB}$ under vertical and lateral excitation.

Despite extensive research on and applications of standoff constrained layer damping, few studies are available on stand-off free layer damping structures [25-27]. Thus, this paper focuses on the stand-off free layer damping structure. We use lightweight, easy-to-form, and economical rigid PU foam as the stand-off layer and rubber as the damping layer material, which are combined with steel plates to prepare stand-off free layer damping cantilever beams. Based on the modal superposition method and the Lagrange equation, the motion equation of the cantilever beam is derived. The dynamic mechanical properties of PU foam and rubber damping materials are tested and analyzed. Through hammering tests in which the damping layer remains constant, the influence of the density and thickness of PU foam on the vibration damping performance of the stand-off free layer damping cantilever beam is analyzed from the perspectives of the amplitude-frequency curve loss factor and modal frequency.

\section{Derivation of Motion Equation}

Motion equation is a mathematical expression for describing the dynamic displacement of a structural system. There are different ways to establish the motion equation of the vibration system. Using the Hamilton principle to establish the equation of motion can avoid vector operations, which is a common method [28-35]. The stand-off free layer damping cantilever beam is shown in Figure 1. It consists of a base layer, a stand-off layer, and a damping layer from bottom to top. The stand-off layer plays a leverage role, which can expand the tension and compression deformation of the damping layer, so the structural damping increases accordingly. In addition, the stand-off layer has the effect of broadening the damping temperature range. Based on the model, a rectangular coordinate system is established, where the length of the cantilever beam is $l$, the width is $b$, and the

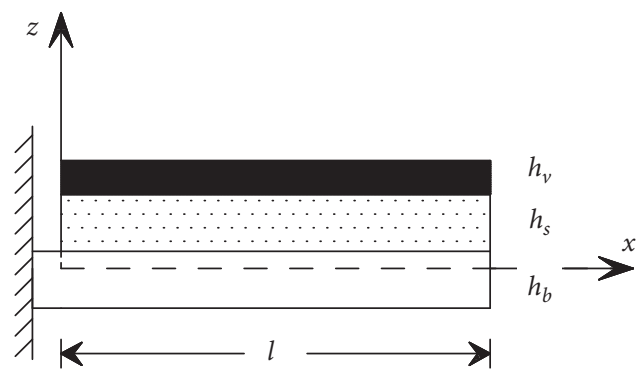

Figure 1: Structural model of the stand-off free layer damping cantilever beam.

thickness of the base layer, the stand-off layer, and the damping layer is $h_{\mathrm{b}}, h_{\mathrm{s}}$, and $h_{\mathrm{v}}$, respectively.

Reference [36] derived the motion equation of the free layer damping cantilever beam with the shear deformation of the damping layer taken into consideration. In this paper, the nonlinear vibration and damping of the cantilever beam are not considered. The following assumptions are made in analyzing the deformation of the stand-off free layer damping cantilever beam. (1) The overall structure produces small deflection deformation, and the resonance remain in the elastic region. (2) The shear deformation of each layer is not considered, and the moment of inertia of the structure is ignored. (3) There is no relative slip between the layers, and the lateral displacement of the layers is equal. (4) The cantilever beam conforms to the plane assumption. Figure 2 shows the local deformation relation of the stand-off free layer damping cantilever beam.

The axial displacement of the base layer, the stand-off layer, and the damping layer on the neutral plane is $u_{b}, u_{s}$, and $u_{v}$, respectively. The lateral displacement of each layer is the same, which is $w$.

According to the assumption, we have

$$
\begin{aligned}
& u_{s}=u_{b}-\frac{1}{2}\left(h_{b}+h_{s}\right) \frac{\partial w}{\partial x}, \\
& u_{v}=u_{b}+\frac{1}{2}\left(h_{b}+2 h_{s}+2 h_{v}\right) \frac{\partial w}{\partial x} .
\end{aligned}
$$

The distance between the neutral axis of the cantilever beam and neutral axis of the base is [37]

$$
D=\frac{E_{s} h_{s} d_{1}+E_{v} h_{v} d_{2}}{E_{b} h_{b}+E_{s} h_{s}+E_{v} h_{v}}
$$

where $E_{b}, E_{s}$, and $E_{v}$ are the elastic modulus of the base layer, the stand-off layer, and the damping layer, respectively, and $d_{1}$ and $d_{2}$ are the distances from the neutral axis of the stand-off layer and the damping layer to the neutral axis of the base layer, respectively.

The total potential energy of the cantilever beam includes deformation potential energy of the base layer, the stand-off layer, and the damping layer. The potential energy of the base layer is

$$
V_{b}=\frac{1}{2} \int_{0}^{l} E_{b}\left[A_{b}\left(\frac{\partial u_{b}}{\partial x}\right)^{2}+I_{b}\left(\frac{\partial^{2} w}{\partial x^{2}}\right)^{2}\right] d x .
$$




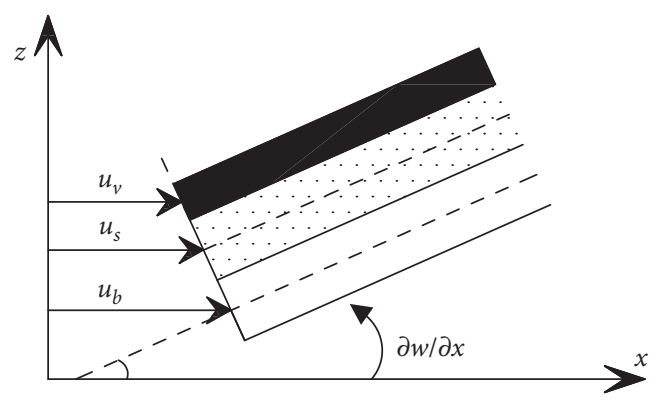

Figure 2: Local deformation relation of the stand-off free layer damping cantilever beam.

The potential energy of the stand-off layer is

$$
V_{s}=\frac{1}{2} \int_{0}^{l} E_{s}\left[A_{s}\left(\frac{\partial u_{s}}{\partial x}\right)^{2}+I_{s}\left(\frac{\partial^{2} w}{\partial x^{2}}\right)^{2}\right] d x
$$

The potential energy of the damping layer is

$$
V_{v}=\frac{1}{2} \int_{0}^{l} E_{v}\left[A_{v}\left(\frac{\partial u_{v}}{\partial x}\right)^{2}+I_{v}\left(\frac{\partial^{2} w}{\partial x^{2}}\right)^{2}\right] d x
$$

where $V_{b}, V_{s}$, and $V_{v}$ are the deformation potential energy of the base layer, the stand-off layer, and the damping layer, respectively, $A_{b}, A_{s}$, and $A_{v}$ are the cross-sectional areas of the three layers, and $I_{b}, I_{s}$, and $I_{v}$ are the cross-sectional moment of inertia of the layers with respect to the neutral axis of the whole structure.

The total kinetic energy of the structure includes the kinetic energy of the base layer, the stand-off layer, and the damping layer. The kinetic energy of the base layer is

$$
T_{b}=\frac{1}{2} \int_{0}^{l} \rho_{b} A_{b}\left[\left(\frac{\partial w}{\partial t}\right)^{2}+\left(\frac{\partial u_{b}}{\partial t}\right)^{2}\right] d x .
$$

The kinetic energy of the stand-off layer is

$$
\begin{aligned}
T_{s} & =\frac{1}{2} \int_{0}^{l} \rho_{s} A_{s}\left[\left(\frac{\partial w}{\partial t}\right)^{2}+\left(\frac{\partial u_{b}}{\partial t}\right)^{2}\right] d x \\
& =\frac{1}{2} \int_{0}^{l} \rho_{s} A_{s}\left[\left(\frac{\partial w}{\partial t}\right)^{2}+\left(\frac{\partial u_{b}}{\partial t}-\frac{1}{2}\left(h_{b}+h_{s}\right) \frac{\partial^{2} w}{\partial x \partial t}\right)^{2}\right] d x .
\end{aligned}
$$

The kinetic energy of the damping layer is

$$
\begin{aligned}
T_{v} & =\frac{1}{2} \int_{0}^{l} \rho_{v} A_{v}\left[\left(\frac{\partial w}{\partial t}\right)^{2}+\left(\frac{\partial u_{v}}{\partial t}\right)^{2}\right] d x \\
& =\frac{1}{2} \int_{0}^{l} \rho_{v} A_{v}\left[\left(\frac{\partial w}{\partial t}\right)^{2}+\left(\frac{\partial u_{b}}{\partial t}-\frac{1}{2}\left(h_{b}+2 h_{s}+2 h_{v}\right) \frac{\partial^{2} w}{\partial x \partial t}\right)^{2}\right] d x
\end{aligned}
$$

where $T_{b}, T_{s}$, and $T_{v}$ are the kinetic energy of the base layer, the stand-off layer, and the damping layer, respectively, and $\rho_{b}, \rho_{s}$, and $\rho_{v}$ are the material density of the three layers, respectively.

The total potential energy of the cantilever beam structure is

$$
V=V_{b}+V_{s}+V_{v}
$$

The total kinetic energy is

$$
T=T_{b}+T_{s}+T_{v} .
$$

We expand the displacement of the cantilever beam structure according to the assumed mode:

$$
\begin{gathered}
w(x, t)=\sum_{i=1}^{n_{w}} w_{i}(x) \varphi_{i}(t), \\
u_{b}(x, t)=\sum_{i=1}^{n_{b}} u_{b i}(x) \alpha_{i}(t) .
\end{gathered}
$$

where $n_{w}$ and $n_{\mathrm{b}}$ are the numbers of half waves according to the accuracy. Let $\bar{L}$ be the Lagrangian function of the beam, and we have

$$
\bar{L}=T-V,
$$

$$
\left\{\begin{array}{l}
\frac{\mathrm{d}}{\mathrm{d} t}\left(\frac{\partial \bar{L}}{\partial \dot{\varphi}_{i}}\right)-\frac{\partial \bar{L}}{\partial \varphi_{i}}=0 \\
\frac{\mathrm{d}}{\mathrm{d} t}\left(\frac{\partial \bar{L}}{\partial \dot{\alpha}_{i}}\right)-\frac{\partial \bar{L}}{\partial \alpha_{i}}=0
\end{array}\right.
$$

Substituting equation (12) into the first equation and the third equation in equation (13), we obtain

$$
\begin{array}{r}
\sum_{j=1}^{n_{w}} M_{\varphi \varphi, i j} \ddot{\varphi}_{j}(t)+\sum_{j=1}^{n_{b}} M_{\varphi \alpha, i j} \ddot{\alpha}_{j}(t)+\sum_{j=1}^{n_{w}} K_{\varphi \varphi, i j} \varphi_{j}(t)=0, \\
\sum_{j=1}^{n_{w}} M_{\alpha \varphi, i j} \ddot{\varphi}_{j}(t)+\sum_{j=1}^{n_{b}} M_{\alpha \alpha, i j} \ddot{\alpha}_{j}(t)+\sum_{j=1}^{n_{w}} K_{\alpha \varphi, i j} \varphi_{j}(t)+\sum_{j=1}^{n_{b}} K_{\alpha \alpha, i j} \alpha_{j}(t)=0,
\end{array}
$$


where

$$
\begin{aligned}
& \begin{cases}M_{\varphi \varphi, i j}=\int_{0}^{l}\left\{\left(\rho_{b} A_{b}+\rho_{s} A_{s}+\rho_{v} A_{v}\right) w_{i} w_{j}+\left[\frac{1}{4} \rho_{s} A_{s}\left(h_{b}+h_{s}\right)^{2}+\frac{1}{4} \rho_{v} A_{v}\left(h_{b}+2 h_{s}+h_{v}\right)^{2}\right] \dot{w}_{i} \dot{w}_{j}\right\} d x & i, j=1,2, \ldots, n_{w}, \\
M_{\varphi \alpha, i j}=\int_{0}^{l}-\frac{1}{2}\left[\rho_{s} A_{s}\left(h_{b}+h_{s}\right)+\rho_{v} A_{v}\left(h_{b}+2 h_{s}+h_{v}\right)\right] \dot{w}_{i} u_{b j} d x & i=1,2, \ldots, n_{w}, j=1,2, \ldots, n_{b}, \\
K_{\varphi \varphi, i j}=\int_{0}^{l}\left[E_{b} I_{b}+E_{s} I_{s}+E_{v} I_{v}+\frac{1}{4} E_{s} A_{s}\left(h_{b}+h_{s}\right)^{2}+\frac{1}{4} E_{v} A_{v}\left(h_{b}+2 h_{s}+h_{v}\right)^{2}\right] w_{i} w_{j} d x & i, j=1,2, \ldots, n_{w}, \\
K_{\varphi \alpha, i j}=\int_{0}^{l}-\frac{1}{2}\left[E_{s} A_{s}\left(h_{b}+h_{s}\right)+E_{v} A_{v}\left(h_{b}+2 h_{s}+h_{v}\right)\right] \ddot{w}_{i} \dot{u}_{b j} d x & i=1,2, \ldots, n_{w}, j=1,2, \ldots, n_{b},\end{cases} \\
& M_{\alpha \varphi, i j}=\int_{0}^{l}-\frac{1}{2}\left[\rho_{s} A_{s}\left(h_{b}+h_{s}\right)+\rho_{v} A_{v}\left(h_{b}+2 h_{s}+h_{v}\right)\right] \dot{w}_{j} u_{b i} d x \quad i=1,2, \ldots, n_{b}, j=1,2, \ldots, n_{w}, \\
& M_{\alpha \alpha, i j}=\int_{0}^{l}\left(\rho_{b} A_{b}+\rho_{s} A_{s}+\rho_{v} A_{v}\right) u_{b i} u_{b j} d x \quad i, j=1,2, \ldots, n_{b}, \\
& K_{\alpha \varphi, i j}=\int_{0}^{l}-\frac{1}{2}\left[E_{s} A_{s}\left(h_{b}+h_{s}\right)+E_{v} A_{v}\left(h_{b}+2 h_{s}+h_{v}\right)\right] w_{j} \dot{u}_{b i} d x \quad i=1,2, \ldots, n_{b}, j=1,2, \ldots, n_{w}, \\
& K_{\alpha \alpha, i j}=\int_{0}^{l}\left(E_{b} A_{b}+E_{s} A_{s}+E_{v} A_{v}\right) \dot{u}_{b i} \dot{u}_{b j} d x \quad i, j=1,2, \ldots, n_{b}
\end{aligned}
$$

Then, the motion equation of the stand-off free layer damping cantilever beam is as follows:

$$
[M]\left[\begin{array}{c}
\ddot{\varphi} \\
\ddot{\alpha}
\end{array}\right]+[K]\left[\begin{array}{l}
\varphi \\
\alpha
\end{array}\right]=0
$$

where

$$
\begin{gathered}
{[M]\left[\begin{array}{ll}
{\left[M_{\varphi \varphi}\right]} & {\left[M_{\varphi \alpha}\right]} \\
{\left[M_{\alpha \varphi}\right]} & {\left[M_{\alpha \alpha}\right]}
\end{array}\right]=0,} \\
{[K]\left[\begin{array}{lll}
{\left[K_{\varphi \varphi}\right]} & {\left[K_{\varphi \alpha}\right]} \\
{\left[K_{\alpha \varphi}\right]} & {\left[K_{\alpha \alpha}\right]}
\end{array}\right]=0,} \\
\varphi=\left[\begin{array}{llll}
\varphi_{1} & \varphi_{2} & \cdots & \varphi_{n_{w}}
\end{array}\right], \\
\alpha=\left[\begin{array}{llll}
\alpha_{1} & \alpha_{2} & \cdots & \alpha_{n_{b}}
\end{array}\right], \\
\varphi=\left[\begin{array}{llll}
\varphi_{1} & \varphi_{2} & \cdots & \varphi_{n_{w}}
\end{array}\right], \\
\alpha=\left[\begin{array}{llll}
\alpha_{1} & \alpha_{2} & \cdots & \alpha_{n_{b}}
\end{array}\right] .
\end{gathered}
$$

We make

$$
\begin{aligned}
& {\left[\begin{array}{l}
\varphi \\
\alpha
\end{array}\right]=\{q(t)\},} \\
& {\left[\begin{array}{c}
\ddot{\varphi} \\
\ddot{\alpha}
\end{array}\right]=\{\ddot{q}(t)\} .}
\end{aligned}
$$

Then, equation (16) is reduced to

$$
[M]\{\ddot{q}(t)\}+[K]\{q(t)\}=0 .
$$

Let the axial and lateral vibrations (both simple harmonic oscillations) be $\omega$. We make $\{\ddot{q}(t)\}=\{\tilde{q}\} e^{i \omega t}$, and then, motion equation (19) of the stand-off free layer damping cantilever beam can be reduced to an eigenvalue equation:

$$
[K]\{\tilde{q}\}=\omega^{2}[M]\{\tilde{q}\} .
$$

By solving the equation, we can obtain the modal frequency $\left(\omega_{i}\right)$ of the cantilever beam.

A stand-off free layer damping cantilever beam model is established by means of experiment. The model materials and dimensions are shown in Table 1 (sample 3\#). The modal frequencies and errors of the first five order bending vibration of the sample are shown in Table 2.

The modal frequencies of the first five order bending vibration obtained by experimental measurement and motion equation solution are very close (with errors ranging 
TABLE 1: Beam parameters and number.

\begin{tabular}{|c|c|c|c|c|c|c|c|}
\hline Sample number & $1 \#$ & $2 \#$ & $3 \#$ & $4 \#$ & $5 \#$ & 6\# & $7 \#$ \\
\hline Base layer material & & & & Q235 & & & \\
\hline layer material & & & & PU foam & & & \\
\hline g material & & & & D-803-Z & & & \\
\hline $\begin{array}{l}\text { Length of all layers, } l \\
(\mathrm{~mm})\end{array}$ & & & & 455 & & & \\
\hline $\begin{array}{l}\text { Width of all layers, } b \\
(\mathrm{~mm})\end{array}$ & & & & 43 & & & \\
\hline $\begin{array}{l}\text { Base layer thickness, } h_{b} \\
(\mathrm{~mm})\end{array}$ & & & & 3 & & & \\
\hline $\begin{array}{l}\text { Damping layer thickness, } \\
h_{v}(\mathrm{~mm})\end{array}$ & & & & 6 & & & \\
\hline $\begin{array}{l}\text { Stand-off layer density, } \rho_{s} \\
\left(\mathrm{~kg} / \mathrm{m}^{3}\right)\end{array}$ & 40 & 80 & 175 & 260 & 260 & 260 & 260 \\
\hline SOL thickness, $h_{s}(\mathrm{~mm})$ & 6 & 6 & 6 & 6 & 9 & 12 & 15 \\
\hline
\end{tabular}

from $2.03 \%$ to $5.09 \%$ ), which proves the validity of the motion equation.

\section{Experiment}

3.1. Material Preparation. The rigid PU foam used in the experiment is manufactured by Qingdao Yongde Polyurethane Co., Ltd. Four types of foam with different densities $\left(40 \mathrm{~kg} / \mathrm{m}^{3}, 80 \mathrm{~kg} / \mathrm{m}^{3}, 175 \mathrm{~kg} / \mathrm{m}^{3}\right.$, and $\left.260 \mathrm{~kg} / \mathrm{m}^{3}\right)$ are selected as the stand-off layer. The damping layer is a D-803-Z rubber damping material provided by Tianjin Rubber Industry Research Institute Co., Ltd., with a thickness of $6 \mathrm{~mm}$, a density of $1420 \mathrm{~kg} / \mathrm{m}^{3}$, and an elastic modulus of $8.3 \times 10^{7} \mathrm{~N} /$ $\mathrm{m}^{2}$. The interlayer adhesive is Qtech-113 from Qingdao Shamu Advanced Material Co., Ltd. The base layer of the cantilever beam is the Q235 steel plate with a thickness of $3.5 \mathrm{~mm}$, a density of $7800 \mathrm{~kg} / \mathrm{m}^{3}$, and an elastic modulus of $2.06 \times 10^{11} \mathrm{~N} / \mathrm{m}^{2}$.

3.2. Dynamic Mechanics Test of Materials. The dynamic mechanical analysis is an important means to study the mechanical properties of viscoelastic materials. Its main purpose is to measure the stiffness and damping of materials under certain conditions and obtain the characteristic parameters related to the structure and molecular motions of materials. The dynamic mechanical analyzer (Netzsch DMA242) was used to analyze the mechanical properties of rubber and PU foam $\left(\rho=175 \mathrm{~kg} / \mathrm{m}^{3}\right)$. The temperature range was $-80 \sim 100^{\circ} \mathrm{C}$, the heating rate was $3^{\circ} \mathrm{C} / \mathrm{min}$, and the test frequency was 5,25 , and $100 \mathrm{~Hz}$.

3.3. Sample Preparation and Hammering Test. The rigid layer on the upper and lower surfaces of the PU foam board was removed, and the middle layer with uniform foaming was taken as the material of the stand-off layer. The Qtech-113 adhesive was evenly coated on the surfaces of PU foam and the rubber damping plate to bond them together. Then, they were compacted gently to drive out the bubbles, thus forming PU-rubber composite damping material. The composite material was bonded with the $3.5 \mathrm{~mm}$ Q235 steel plate by adhesive to prepare the stand-off free layer damping cantilever beams. The beams were placed in an oven of $40^{\circ} \mathrm{C}$ for curing for 24 hours and then taken out. After being stored for 24 hours at room temperature $\left(20 \sim 25^{\circ} \mathrm{C}\right)$, they were ready for the hammering test.

The cantilever beams are numbered as in Table 1. Beams $1 \#$ to $4 \#$ have the same parameters except the density of the stand-off layer, and beams $4 \#$ to $7 \#$ have the same parameters except the thickness of the stand-off layer.

The test and analysis system includes cantilever beams, fixture, force hammer, accelerometer, signal acquisition device, control, and analysis system (includes data analysis software), as shown in Figure 3. The detailed information of the test and analysis system is shown in Table 3.

The excitation point of the force hammer and the vibration pick-up point of the accelerometer are located in the middle of the steel plate, $25 \mathrm{~mm}$ from the fixed end and the free end of the beam, respectively. In order to ensure the resonance of the cantilever beam in the elastic region, the hammering tests adopt small exciting force to avoid large deformation of the cantilever. The data of three repeated hammer strikes were taken for the final analysis. The analysis frequency was $1250 \mathrm{~Hz}$, and the experimental temperature was $23.5^{\circ} \mathrm{C}$. Through transfer function analysis of the collected data, the transfer function curves of the beams were obtained, and the modal frequency and loss factor were obtained by the INV method.

\section{Results and Discussion}

4.1. Dynamic Mechanical Analysis of Materials. The damping capacity of viscoelastic material is characterized by its dynamic mechanical properties, and the basic parameters are dynamic modulus $M^{*}$ (storage modulus $M^{\prime}$ and loss modulus $M^{\prime}$ ) and loss factor $\beta$, as shown in the following equations, where $i$ is the imaginary unit:

$$
\begin{gathered}
M^{*}=M^{\prime}+i M^{\prime \prime}, \\
\beta=\tan \delta=\frac{M^{\prime \prime}}{M^{\prime}} .
\end{gathered}
$$

The dynamic modulus (storage modulus and loss modulus) of D-803-Z and PU foam $\left(175 \mathrm{~kg} / \mathrm{m}^{3}\right)$ at different frequencies is shown in Figures 4 and 5, respectively, and the variation of loss factor is shown in Figures 6 and 7.

As can be seen from Figure 4, when the temperature is between $-80^{\circ} \mathrm{C}$ and $-40^{\circ} \mathrm{C}, \mathrm{D}-803-\mathrm{Z}$ is in the glassy state with a large storage modulus. The internal molecular chains are "frozen," and it is difficult to produce relative sliding. With the rise of temperature, the storage modulus decreases slowly, while the loss modulus continues to increase. When the temperature rises from $-40^{\circ} \mathrm{C}$ to $20^{\circ} \mathrm{C}$, the storage modulus decreases rapidly, and the loss modulus reaches a peak in this temperature domain. It indicates that the material has been in a glass transition region and that the internal chains start to change from a "frozen" state to an "unfrozen" state. At this time, although the molecular chains are capable of moving, the movement process needs to overcome the large internal friction, and mechanical energy 
TABle 2: Comparison between the modal frequencies of the first five orders of the cantilever beam.

\begin{tabular}{lccc}
\hline Modal order $i$ & Experiment measurement $(\mathrm{Hz})$ & Motion equation solution $(\mathrm{Hz})$ & Error $(\%)$ \\
\hline 1 & 11.94 & 12.48 & 4.52 \\
2 & 74.41 & 78.20 & 5.09 \\
3 & 225.59 & 218.97 & 2.94 \\
4 & 444.34 & 429.10 & 3.43 \\
5 & 724.02 & 709.33 & 2.03 \\
\hline
\end{tabular}

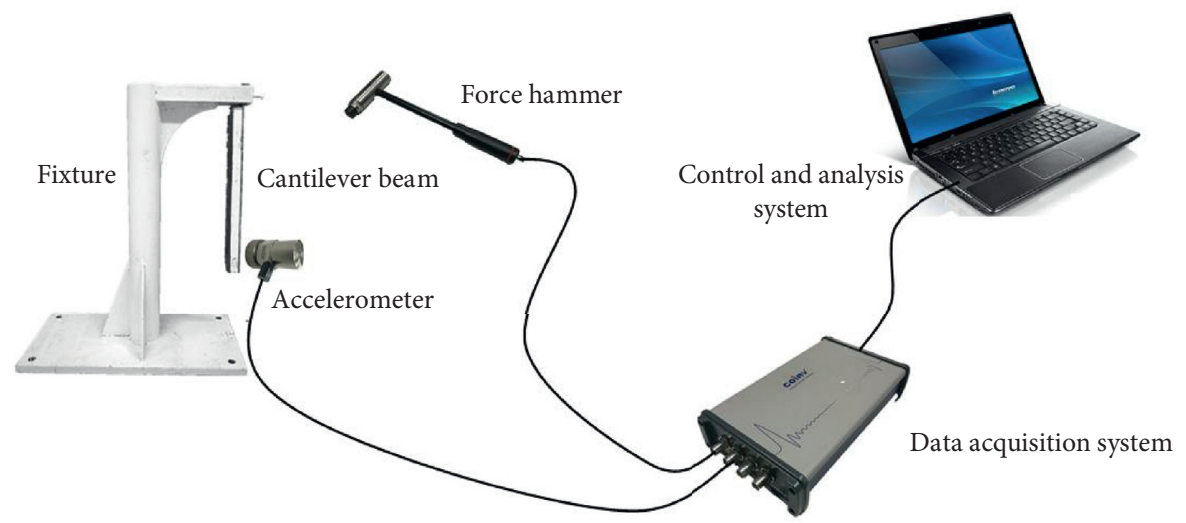

FIgURE 3: Test and analysis system.

TABLE 3: Beam parameters and number.

\begin{tabular}{lcc}
\hline Experimental device & Manufacturer & Device version \\
\hline $\begin{array}{l}\text { Force hammer } \\
\text { Signal acquisition }\end{array}$ & China Orient Institute of Noise and Vibration & INV313 \\
$\begin{array}{l}\text { Data analysis software } \\
\text { Accelerometer }\end{array}$ & Lance Measurement Technologies CO., LTD & Coinv Dasp V11 \\
Fixture cantilever beams & Self-made & LC0103 \\
\hline
\end{tabular}

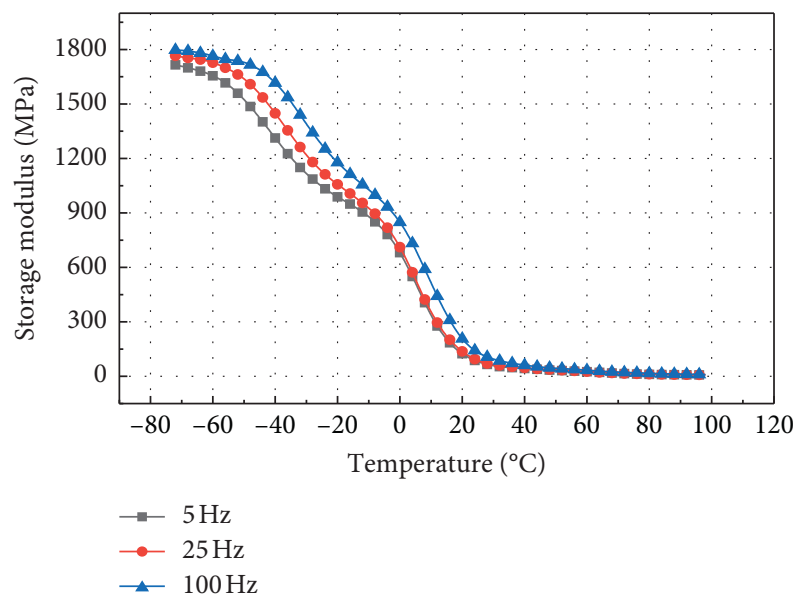

(a)

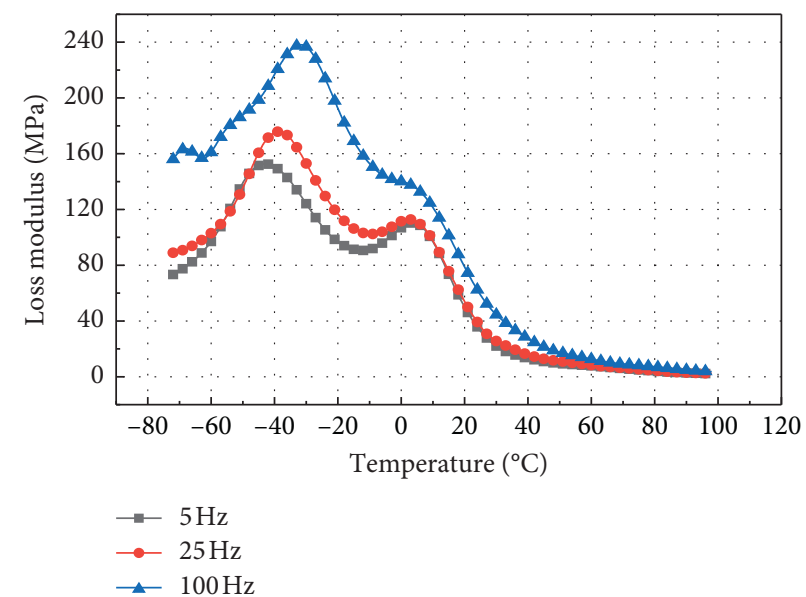

(b)

FIGURE 4: Dynamic modulus temperature spectrum of D-803-Z at different frequencies. (a) Storage modulus. (b) Loss modulus. 


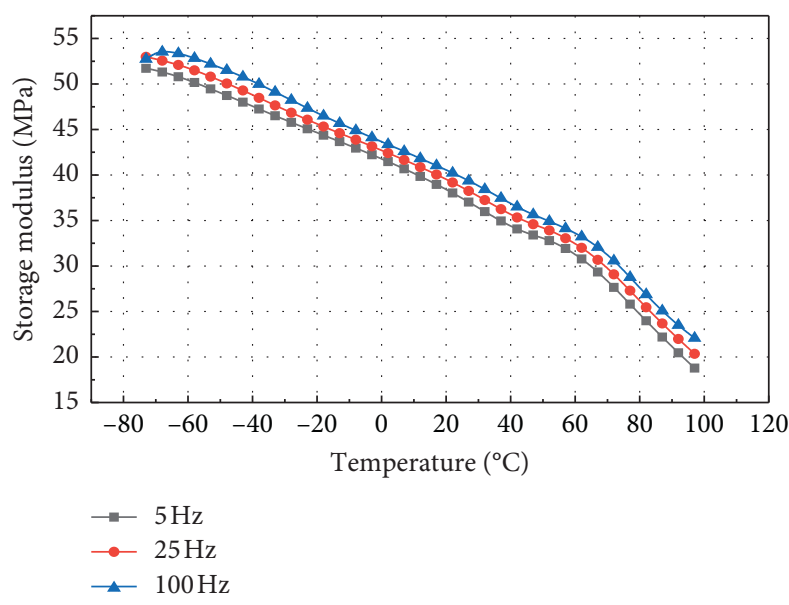

(a)

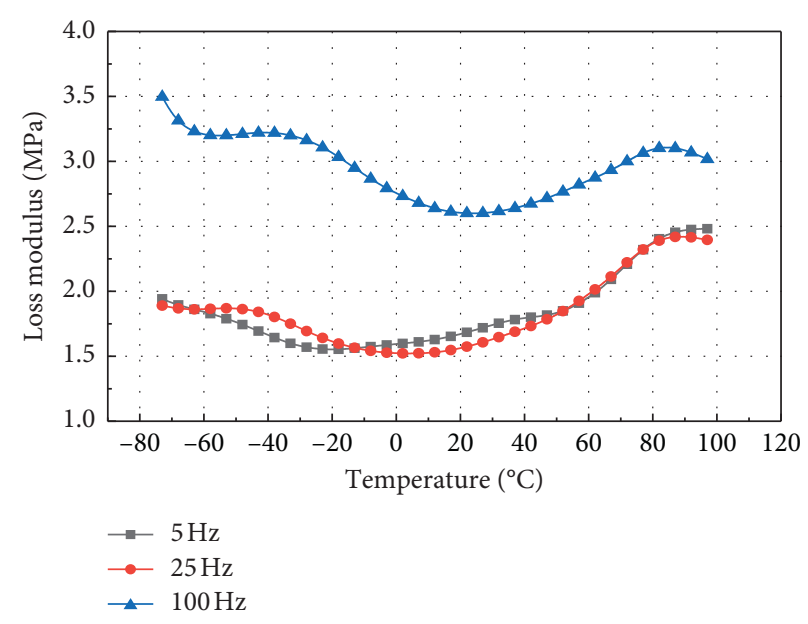

(b)

Figure 5: Dynamic modulus temperature spectrum of PU foam $\left(175 \mathrm{~kg} / \mathrm{m}^{3}\right)$ at different frequencies. (a) Storage modulus. (b) Loss modulus.

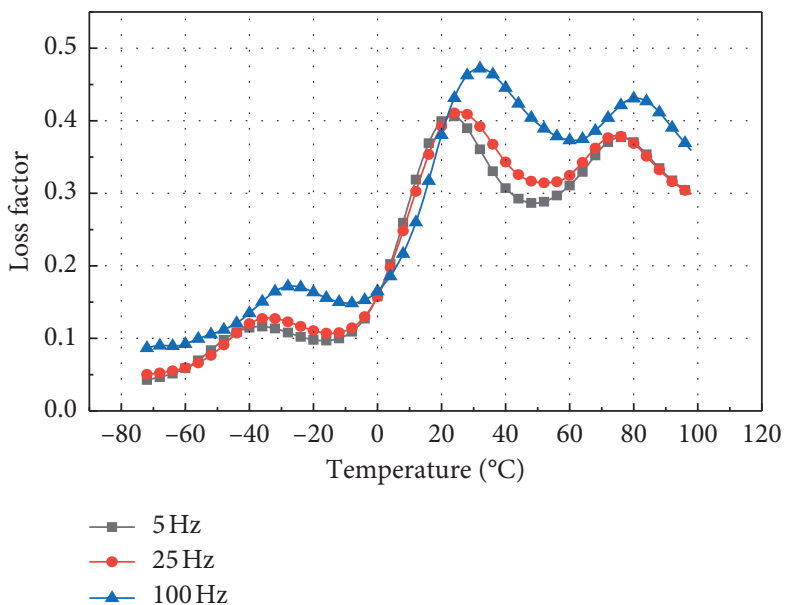

(a)

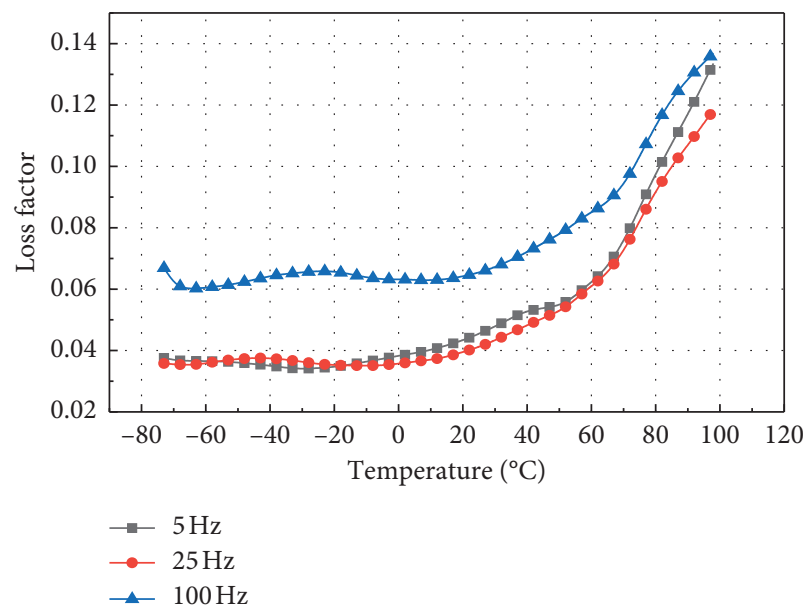

(b)

Figure 6: Loss factor spectrum at different frequencies. (a) D-803-Z. (b) PU foam $\left(175 \mathrm{~kg} / \mathrm{m}^{3}\right)$.

is converted into heat energy through internal friction between molecules. After the external force is removed, the chains cannot return to the original state completely, resulting in permanent deformation. Therefore, the movement is irreversible, and the material exhibits viscous behavior. The portion of mechanical energy applied to the viscous component by the external force cannot return to outside and is dissipated as heat, thus reducing vibration by damping. When the temperature is higher than $20^{\circ} \mathrm{C}$, the storage modulus and loss modulus continue to decrease and then gradually stabilize.

As shown in Figure 5, when the temperature rises from $-80^{\circ} \mathrm{C}$ to $60^{\circ} \mathrm{C}$, the storage modulus of PU foam $\left(175 \mathrm{~kg} / \mathrm{m}^{3}\right)$ shows a decreasing trend, and the loss modulus decreases before increasing, displaying a " $U$ " change. When the temperature exceeds $60^{\circ} \mathrm{C}$, the storage modulus of the material decreases faster, while the loss modulus increases gradually, and the material begins to enter into a glass transition region. In addition, when the testing frequency is increased to $100 \mathrm{~Hz}$, the storage modulus does not change significantly, while the loss modulus is significantly improved, which shows that the loss modulus of polyurethane foam has obvious frequency dependence. Compared with low-frequency vibration, polyurethane foam has a more obvious damping effect on high-frequency vibration.

As shown in Figure 6(a), the loss factor of D-803-Z exceeds 0.3 at $15 \sim 90^{\circ} \mathrm{C}$, with a wide damping temperature domain, and two peaks occur at $20 \sim 40^{\circ} \mathrm{C}$ displaying a "saddle" shape. This is because the D-803-Z rubber damping material is a kind of the semicompatible blend system with macroscopic homogeneous and microscopic heterogeneous phases. Thus, a double glass transition phenomenon occurs, resulting in two loss factor peaks overlapping each other [4]. Mixing rubber with other polymers with high glass 

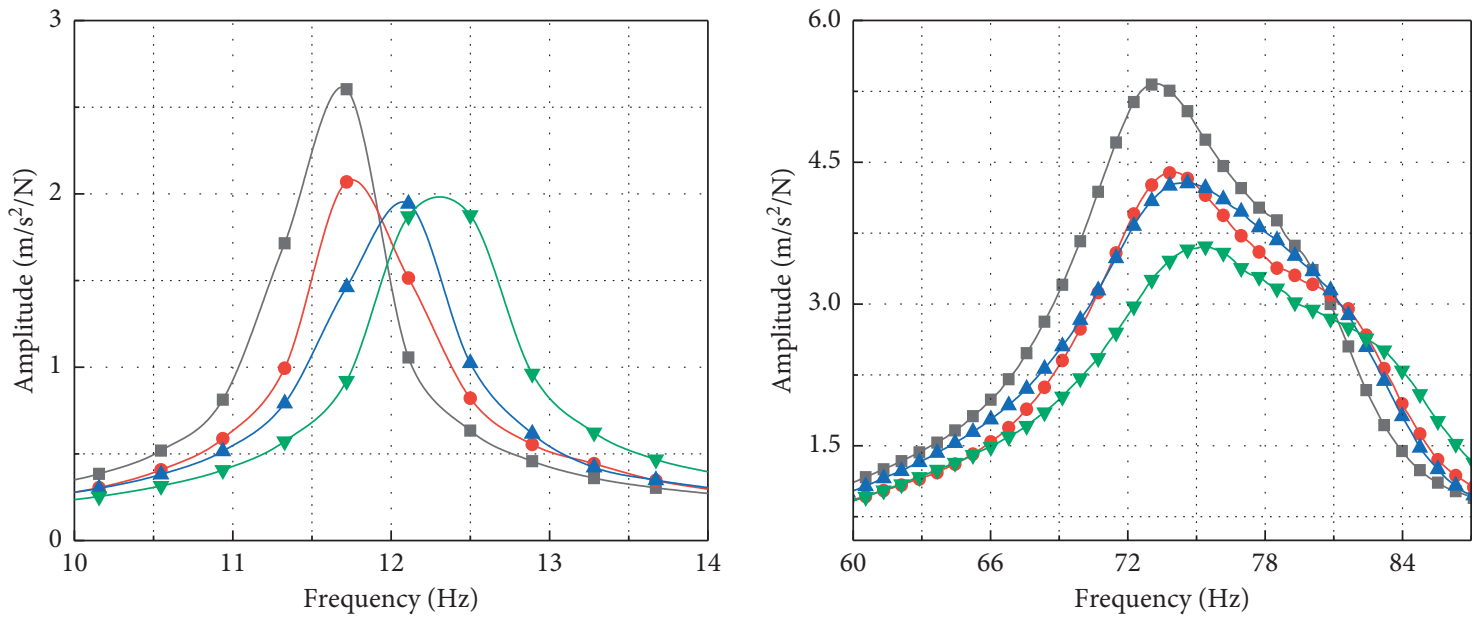

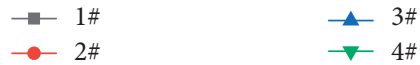

(a)

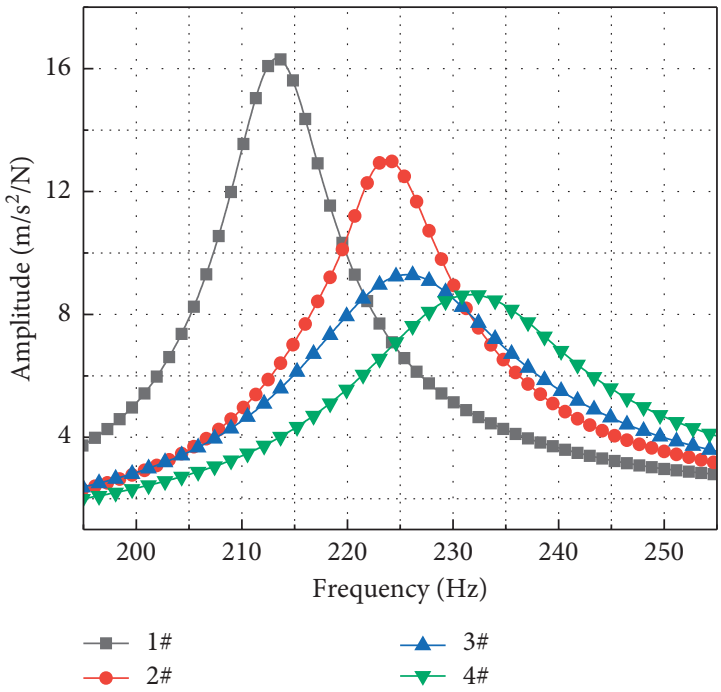

(c)

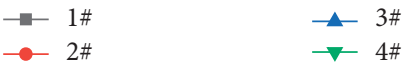

(b)

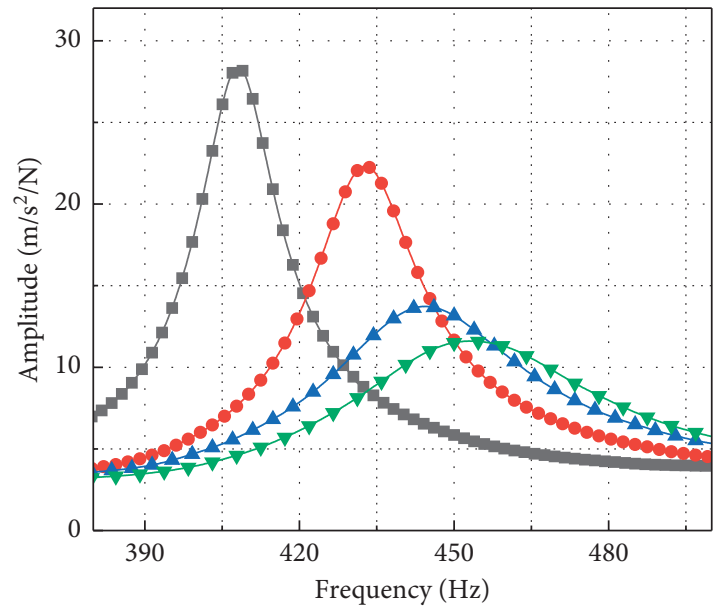

$\rightarrow-1 \#$

$-3 \#$
$-\quad 4 \#$

(d)

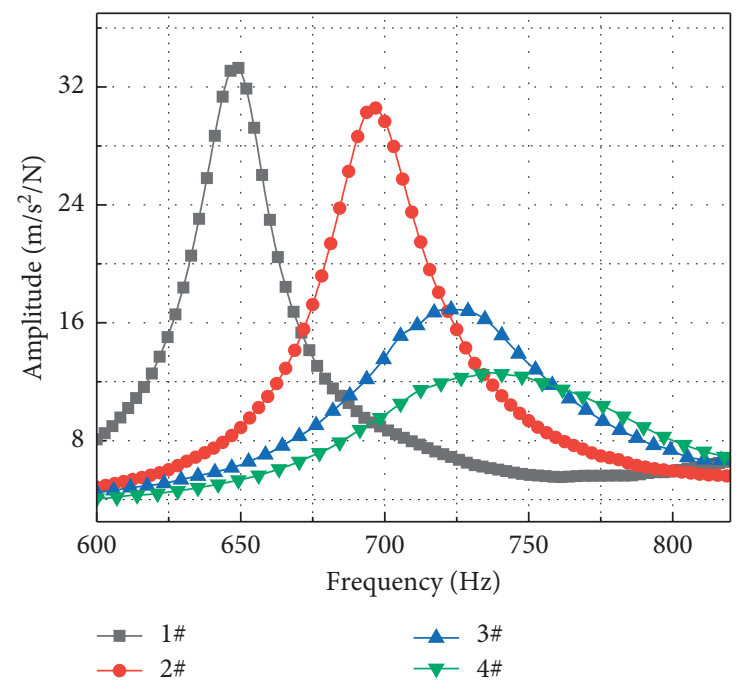

(e)

Figure 7: First five transfer function curves of cantilever beams 1\# 4\# (experimental temperature: $\left.23.5^{\circ} \mathrm{C}\right)$. (a) Mode 1. (b) Mode 2. (c) Mode 3. (d) Mode 4. (e) Mode 5. 
transition temperature $\left(T_{g}\right)$ is an effective method to improve the damping properties of rubber materials. After blending, the $T_{g}$ of polymer (such as plastic) will move and the damping peak will decrease. The addition of high $T_{g}$ viscoelastic polymer increases $T_{g}$ of the rubber system. By adjusting the blending ratio of each component, the effective damping temperature range of the blend can be extended beyond the glass transition region of each homopolymer, so as to expand the effective damping temperature range.

The loss factor of $\mathrm{PU}$ foam is in the range of $-80 \sim 100^{\circ} \mathrm{C}$ (as shown in Figure 6(b), which tends to increase with the rise of temperature, especially after $50^{\circ} \mathrm{C}$. At around $20^{\circ} \mathrm{C}$, the loss factor of PU foam is about an order of magnitude smaller than that of rubber; so, the main energy consumer of the cantilever beam structure is rubber. The PU foam mainly plays the role of expanding the deformation of the damping layer and auxiliary energy dissipation. In addition, the loss modulus and loss factor of rubber and foam material at $100 \mathrm{~Hz}$ are improved considerably, as compared with $5 \mathrm{~Hz}$ and $25 \mathrm{~Hz}$. It indicates that the damping performance of the material is frequency dependent to a great extent.

4.2. Effect of Foam Density on Vibration Performance. The PU foam density of cantilever beams $1 \# \sim 4 \#$ are $40 \mathrm{~kg} / \mathrm{m}^{3}$, $80 \mathrm{~kg} / \mathrm{m}^{3}, 175 \mathrm{~kg} / \mathrm{m}^{3}$, and $260 \mathrm{~kg} / \mathrm{m}^{3}$, respectively, all other parameters being the same. The first five transfer function curves are shown in Figure 7. When the density of the PU foam stand-off layer increases from $40 \mathrm{~kg} / \mathrm{m}^{3}$ to $80 \mathrm{~kg} / \mathrm{m}^{3}$, $175 \mathrm{~kg} / \mathrm{m}^{3}$, and $260 \mathrm{~kg} / \mathrm{m}^{3}$ in sequence, the vibration response peaks of the first five modes all show a decreasing trend. Low-density PU foam has a large porosity and a low modulus and is apt to deform, which is not conducive to the transfer of the deformation generated by the vibration (especially the high frequency vibration with small deformation) of the base layer to the damping layer. As the density of PU foam increases, the modulus ratio of foam to rubber increases, which helps the vibration of the substrate to be transferred more efficiently to the damping layer for energy dissipation. Thus, the structure exhibits better damping performance, in agreement with the results in [14].

Moreover, when the density of foam increased from $40 \mathrm{~kg} / \mathrm{m}^{3}$ to $80 \mathrm{~kg} / \mathrm{m}^{3}$ and $175 \mathrm{~kg} / \mathrm{m}^{3}$, the vibration peaks of the first five orders decreased sharply. When the density was further increased to $260 \mathrm{~kg} / \mathrm{m}^{3}$, the peak decline of most modes was reduced obviously. Take the third order and the fourth order for examples; when the foam density changed from $40 \mathrm{~kg} / \mathrm{m}^{3}$ to $175 \mathrm{~kg} / \mathrm{m}^{3}$, the peak value decreased by $42 \%$ and $52 \%$, respectively. When it was increased to $260 \mathrm{~kg} / \mathrm{m}^{3}$, the peak value decreased by $47 \%$ and $59 \%$, respectively. The change of the vibration peak value was relatively small, as compared with the foam composite structure of $175 \mathrm{~kg} / \mathrm{m}^{3}$. It can be seen that increasing the density of the foam is helpful to improve the vibration damping performance of cantilever beam. When the foam density increases to a certain level, the change of modal vibration peak tends to be gentle, and the vibration suppression effect tends to be stable.
The modal frequencies and loss factors of the first five orders of $1 \# \sim 4 \#$ beams are shown in Table 4 . The increase of foam density leads to increased elastic modulus, which significantly increases the overall stiffness of the cantilever beam, thus causing its modal frequency to move towards high frequency. Meanwhile, the loss factor rises, and the damping performance is improved.

In addition, compared with $1 \#$, the modal frequency of the first five orders of $4 \#$ increased by $6.40 \%, 2.68 \%, 8.42 \%$, $12.16 \%$, and $15.99 \%$, respectively, and the loss factor increased by $79.74 \%, 36.71 \%, 113.19 \%, 147.61 \%$, and $172.78 \%$, respectively. With the increase of the modal order, the change rate of its modal frequency and loss factor increased significantly (except for the second order), and the same is true for $2 \#$ and $3 \#$. This shows that a higher density of the foam layer has more an obvious influence on the higher order mode of the cantilever beam because rubber and PU foam are strongly frequency dependent. The higher the frequency, the greater the storage modulus and the loss factor.

In summary, given the same thickness $(6 \mathrm{~mm})$ of the foam layer, increasing its density is helpful to improve the vibration reduction performance of the stand-off free layer damping cantilever beam. In this study, the foam with a density of $260 \mathrm{~kg} / \mathrm{m}^{3}$ has the best effect.

4.3. Effect of Foam Thickness on Vibration Performance. Based on the above results, PU foam with a density of $260 \mathrm{~kg} /$ $\mathrm{m}^{3}$ was selected as the stand-off layer to obtain stand-off free layer damping cantilever beams with different thicknesses of PU foam. For example, for $4 \# \sim 7 \#$, the thicknesses of the foam stand-off layer are $6 \mathrm{~mm}, 9 \mathrm{~mm}, 12 \mathrm{~mm}$, and $15 \mathrm{~mm}$, respectively, all other parameters of the cantilever beam being the same. The first five transfer function curves are shown in Figure 8.

It can be seen that the peak value of the first five order shows a downward trend with the increase of the thickness of the stand-off layer. The metal itself consumes little energy, and the vibration energy of the substrate is all transmitted to the stand-off layer. A small portion of the energy is dissipated by the stand-off layer, while most of it is transmitted to the damping layer to be dissipated. According to equation (2), the distance between the neutral axis of the damping layer and the neutral axis of the cantilever beam is

$$
p=\frac{1}{2} h_{v}+h_{s}+\frac{1}{2} h_{b}-\frac{E_{s} h_{s} d_{1}+E_{v} h_{v} d_{2}}{E_{b} h_{b}+E_{s} h_{s}+E_{v} h_{v}} .
$$

That is,

$$
p=\frac{1}{2} \cdot \frac{E_{s} h_{s}^{2}+\left(E_{s} h_{v}+2 E_{b} h_{b}\right) h_{s}+\left(h_{v}+h_{b}\right) E_{b} h_{b}}{E_{b} h_{b}+E_{s} h_{s}+E_{v} h_{v}} .
$$

With the increase of the thickness $\left(h_{s}\right)$ of the stand-off layer, the distance $(p)$ processed by the damping layer increases. Therefore, for the same deformation of the base layer, increased deformation of the damping layer leads to the increase of the relative slip of the molecular chain segments and increase of the energy consumption of the 
TABle 4: Modal frequencies and loss factors of samples $1 \# \sim 4 \#$ (experimental temperature: $23.5^{\circ} \mathrm{C}$ ).

\begin{tabular}{lcccccccccc}
\hline \multirow{2}{*}{ Sample number } & \multicolumn{4}{c}{ Modal frequencies $(\mathrm{Hz})$} \\
& Mode 1 & Mode 2 & Mode 3 & Mode 4 & Mode 5 & Mode 1 & Mode 2 & Mode 3 & Mode 4 & Mode 5 \\
\hline 1\# & 11.56 & 73.24 & 213.48 & 408.01 & 648.24 & 0.0306 & 0.1087 & 0.0455 & 0.0355 & 0.0360 \\
2\# & 11.88 & 74.02 & 223.63 & 432.62 & 695.90 & 0.0429 & 0.1104 & 0.0501 & 0.0406 & 0.0438 \\
3\# & 11.94 & 74.41 & 225.59 & 444.34 & 724.02 & 0.0465 & 0.1446 & 0.0869 & 0.0842 & 0.0847 \\
4\# & 12.30 & 75.20 & 231.45 & 457.62 & 751.88 & 0.0550 & 0.1486 & 0.0970 & 0.0879 & 0.0982 \\
\hline
\end{tabular}

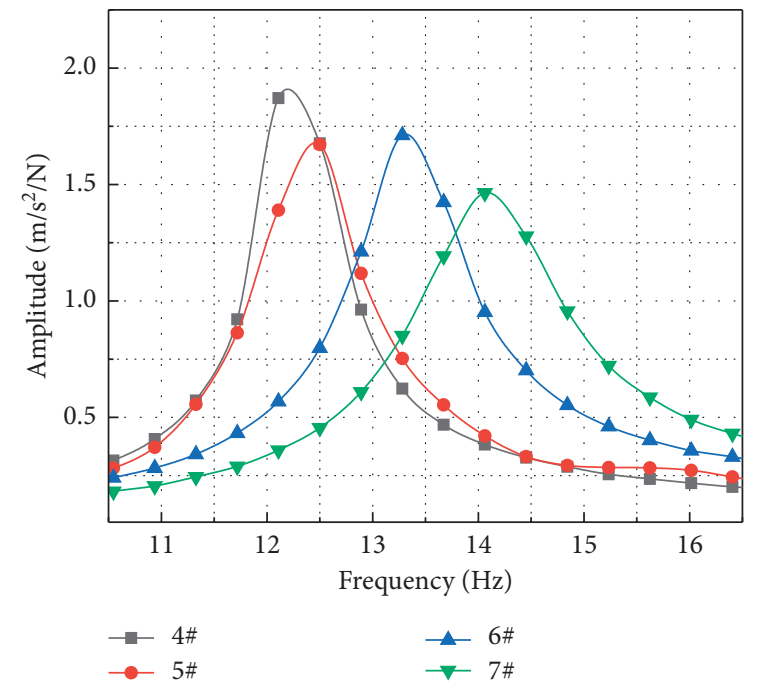

(a)

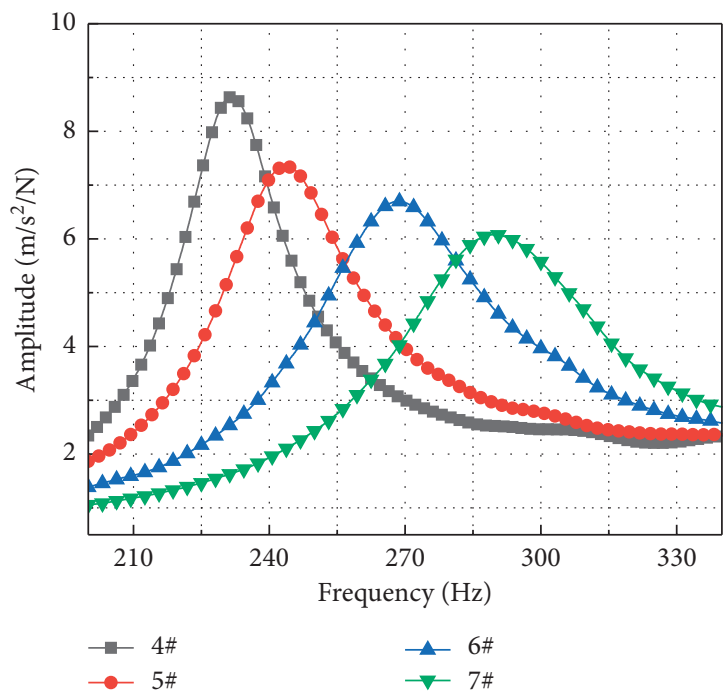

(c)
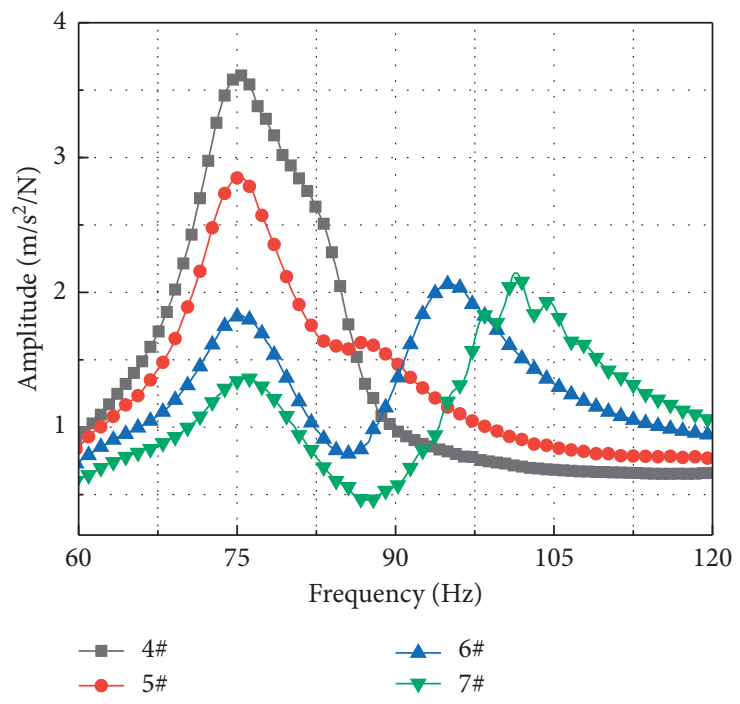

(b)

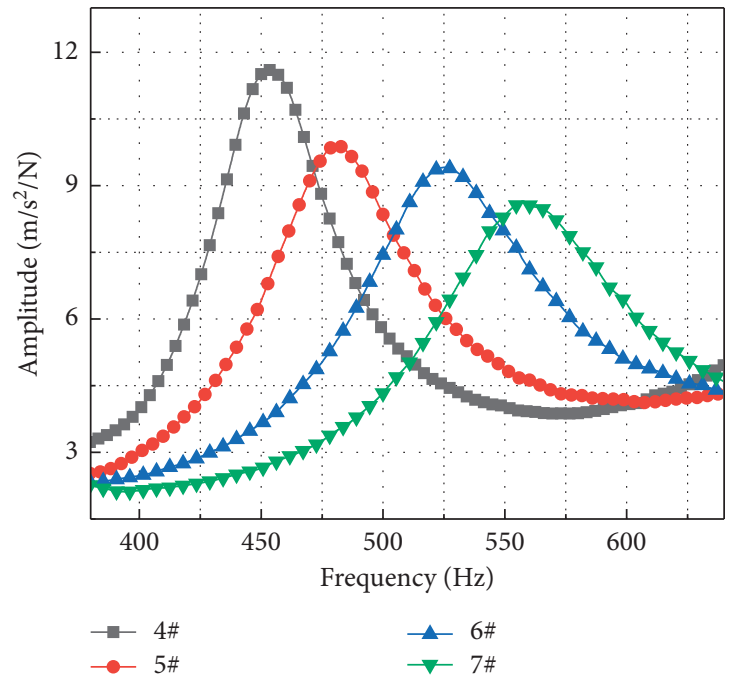

(d)

Figure 8: Continued. 


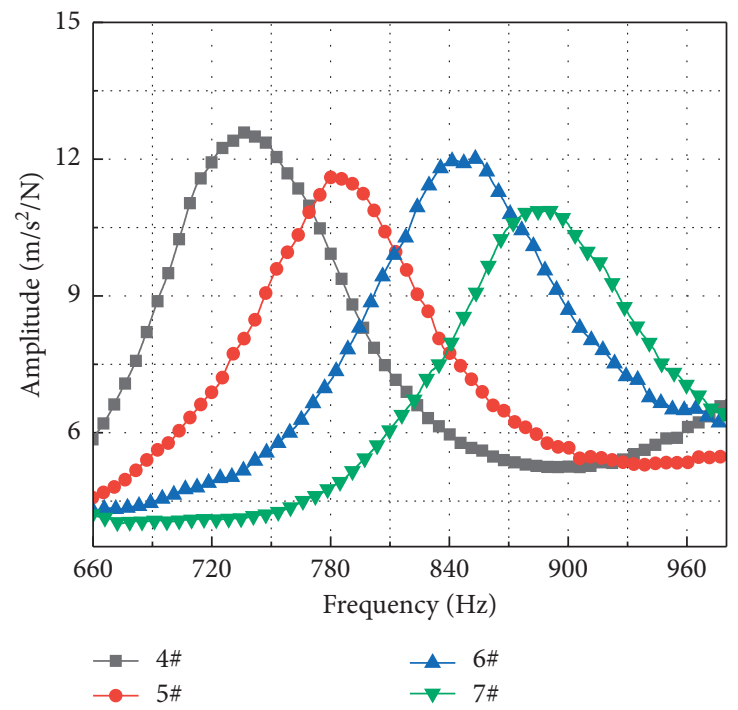

(e)

Figure 8: First five transfer function curves of cantilever beams 4\# 7\# (experimental temperature: 23.5 $5^{\circ}$ ). (a) Mode 1 . (b) Mode 2. (c) Mode 3. (d) Mode 4. (e) Mode 5.

TABLE 5: Modal frequencies and loss factors of $4 \# \sim 7$ \# (experimental temperature: $23.5^{\circ} \mathrm{C}$ ).

\begin{tabular}{lcccccccccc}
\hline \multirow{2}{*}{ Sample number } & \multicolumn{4}{c}{ Modal frequencies $(\mathrm{Hz})$} \\
& Mode 1 & Mode 2 & Mode 3 & Mode 4 & Mode 5 & Mode 1 & Mode 2 & Mode 3 & Mode 4 & Mode 5 \\
\hline 4\# & 12.30 & 75.20 & 231.45 & 457.62 & 751.88 & 0.0550 & 0.1486 & 0.0970 & 0.0879 & 0.0982 \\
5\# & 12.32 & 75.20 & 243.56 & 481.06 & 781.45 & 0.0661 & 0.1235 & 0.1160 & 0.1234 & 0.1230 \\
6\# & 13.46 & 75.20 & 268.56 & 525.20 & 843.56 & 0.0684 & 0.1318 & 0.1392 & 0.1400 & - \\
7\# & 14.24 & 75.98 & 289.65 & 557.62 & 884.57 & 0.0871 & 0.1440 & 0.1478 & 0.1428 & - \\
\hline
\end{tabular}

damping layer. Therefore, the vibration damping performance is improved, and the vibration response is reduced. Moreover, PU foam itself consumes some energy; so, increasing the thickness of the stand-off layer not only extends the transmission distance of vibration but also acts to increase the thickness of the damping layer to some extent, which is conducive to improving the damping performance of the structure.

As the thickness of the stand-off layer increases, another vibration peak gradually emerges near the second-order resonance peak. The reason might be that the increase in the overall thickness of the cantilever beam and the upward movement of the neutral axis cause the structure to be excited into a torsional mode near the second-order bending mode, which partially overlaps with the resonance peak of the bending mode. Moreover, the thicker the stand-off layer is and the farther the neutral axis is from the base layer, the more likely the torsional mode is to be excited and the more obvious it is. As a result, the modal frequency and loss factor of the second mode are different from those of other modes.

The modal frequencies and loss factors of the first five orders of cantilever beams $4 \# \sim 7 \#$ are shown in Table 5 .

Compared with $1 \#$, the modal frequency of the first five orders of $4 \#$ increased by $15.77 \%, 1.04 \%, 25.15 \%, 21.85 \%$, and $17.65 \%$, respectively, and the loss factor of the first four orders increased by $58.36 \%, 3.10 \%, 52.37 \%$, and $62.46 \%$, respectively. With the increase of the thickness of the standoff layer, the modal frequencies move towards high frequency, which due to the bending modal frequency of the cantilever beam is [4]

$$
f_{n}=\frac{(2 n-1 / 2 \pi)^{2}}{2 \pi l^{2}} \sqrt{\frac{E I}{\rho S}} .
$$

When the thickness of the stand-off layer changes, the parameter that determines its natural vibration frequency is $I / S$. Thus, we have

$$
f_{n} \propto h_{v}
$$

With the increase of the thickness of the stand-off layer, its natural vibration frequency increases, thus causing the natural vibration rate of the structure to rise. The increase of foam layer thickness significantly increases the loss factor of the cantilever beam and improves the damping performance. The results are in good agreement with the previous analysis results.

To sum up, within the scope of this study, increasing the thickness of the foam layer can further improve the damping 
performance, and the foam layer with a thickness of $15 \mathrm{~mm}$ has the best vibration damping effect.

\section{Conclusions}

(1) The motion equation of the stand-off free layer damping cantilever beam is derived by means of the modal superposition principle and the Lagrange equation. A comparison with the experiment results proves the accuracy of the motion equation.

(2) D-803-Z is a blend rubber with double glass transition temperature, which has a high loss factor and good damping temperature domain, and is a major energy consumer in the whole composite structure. The loss factor of PU foam is smaller than that of damping rubber, which mainly plays the role of expanding the deformation of the damping layer and auxiliary energy dissipation. Moreover, the dynamic mechanical properties of the two materials show obvious frequency dependence.

(3) Increasing the density and thickness of the PU foam stand-off layer within a certain range can improve the vibration suppression performance of the standoff free layer damping cantilever beam and enhance the overall stiffness of the cantilever beam in the meanwhile, making the modal frequency get higher. Therefore, without considering the additional mass and thickness of the structure, we can increase the density and thickness of PU foam appropriately to improve the vibration damping performance of the stand-off free layer damping cantilever beam.

\section{Data Availability}

The data used to support the findings of this study are available from the corresponding author upon request.

\section{Conflicts of Interest}

The authors declare that there are no conflicts of interest regarding the publication of this paper.

\section{Acknowledgments}

The authors thank the financial support provided by the National Natural Science Foundation of China (51578298).

\section{References}

[1] G. Cai, "Application and process technology of damping material for naval vessels," Development and Application of Materials, vol. 24, no. 6, pp. 76-79, 2009.

[2] Y. Wang, X. Chen, and G. Huang, "The latest research progress of multiplex damping materials," Materials Review, vol. 18, no. 10, pp. 54-56, 2004.

[3] W. Huang and F. Zhan, "Studies on the dynamic mechanical and vibration damping properties of polyether urethane and epoxy composites," Journal of Applied Polymer Science, vol. 50, no. 2, pp. 277-283, 1993.
[4] G. Chang, Viscoelastic Damping Materials, National Defense Industry Press, Beijing, China, 2012.

[5] X. Ren, L. Hong, C. Gao, S. Li, and D. Chen, "The research progress of marine damping materials," Ship Science and Technology, vol. 39, no. 11, 2017.

[6] H. Liu, "Application of damping material on surface vessels," Naval Architecture and Ocean Engineering, vol. 32, no. 1, pp. 74-78, 2016.

[7] J. M. Yellin, I. Y. Shen, P. J. Reinhall, and P. Y. H. Huang, "An analytical and experimental analysis for a one-dimensional passive stand-off layer damping treatment," Journal of Vibration and Acoustics, vol. 122, pp. 440-447, 2004.

[8] E. M. Kerwin, B. Beranek, and N. Inc, "Ideal spaced damping treatments for flexural waves," Acoustical Society of America, vol. 31, no. 6, p. 846, 1959.

[9] J. M. Yellin, I. Y. Shen, P. J. Reinhall, and P. Y. H. Huang, "An experimental investigation of a passive stand-off layer damping treatment applied to an Euler-Bernoulli beam," SPIE Conference on Passive Damping and Isolation, vol. 3672, pp. 228-233, 1999.

[10] J. M. Yellin, I. Y. Shen, and P. J. Reinhall, "Analytical model for a one-dimensional slotted stand-off layer damping treatment," Proceedings of SPIE, vol. 3989, pp. 132-141, 2000.

[11] B.-J. Yan, Z.-D. Zhao, B.-X. Lang, and P. Xu, "Damping characteristic analysis and application of a tubular stand-offlayer sandwiched structure," Noise Control Engineering Journal, vol. 65, no. 6, pp. 522-530, 2017.

[12] B. Yan, W. Zhang, Z. Li, and D. Sun, "Distributed parameter transfer function method for dynamic response of a constrained damping structure with transition layer," Journal of Vibration and Shock, vol. 35, no. 5, pp. 186-190, 2016.

[13] W. Zhang, D. Sun, B. Yan, Z. Li, and B. Sun, "Complex stiffness method of loss factor for constrained damping structure with transition layer," Journal of Basic Science and Engineering, vol. 24, pp. 1296-1307, 2016.

[14] S. Kumar, R. Kumar, and R. Sehgal, "Enhanced ACLD treatment using stand-off-layer: FEM based design and experimental vibration analysis," Applied Acoustics, vol. 72, no. 11, pp. 856-872, 2011.

[15] S. Yi, S. He, and J. Wang, "Study on vibration resistance of constraint stand-off layer damping structures based on temperature-frequency effects," Noise and Vibration Control, vol. 38, no. 3, pp. 181-185, 2018.

[16] S. Yi, S. He, and J. Wang, "Application of particle swarm optimization in dynamic optimization of constrained standoff layer damping structure," Chinese Journal of Ship Research, vol. 13, no. 1, pp. 31-37, 2018.

[17] M. R. Garrison, R. N. Miles, J. Q. Sun, and W. Bao, "Random response of a plate partially covered by a constrained layer damper," Journal of Sound and Vibration, vol. 172, no. 2, pp. 231-245, 1994.

[18] H. Shi and D. Zhao, "Reducing vibration and optimization design of beam with a stand-off constrained layer damping patch," Journal of Machine Design, vol. 27, no. 12, pp. 79-84, 2010.

[19] D. Zhao and H. Shi, "Reduction of vibration and optimization of beams with constrained layer damping patch based on genetic algorithm," Mechanics in Engineering, vol. 33, no. 4, pp. 13-16, 2011.

[20] M. D. Rao, "Recent applications of viscoelastic damping for noise control in automobiles and commercial airplanes," Journal of Sound and Vibration, vol. 262, no. 3, pp. 457-474, 2003. 
[21] D. Meng, Preparation and Properties of Constrained Damping Composites, Wuhan University of Technology, Wuhan, China, 2010.

[22] C. Zhao and P. Wang, "Theoretical modelling and effectiveness study of slotted stand-off layer damping treatment for rail vibration and noise control," Shock and Vibration, vol. 2015, Article ID 716382, , 2015.

[23] C. Zhao, P. Wang, Q. Yi, X. Sheng, and J. Lu, “A detailed experimental study of the validity and applicability of slotted stand-off layer rail dampers in reducing railway vibration and noise," Journal of Low Frequency Noise, Vibration and Active Control, vol. 37, no. 4, pp. 886-910, 2018.

[24] C. Zhao and P. Wang, "Theoretical analysis and experimental study on silent rail with slotted stand-off layer," Journal of the China Railway Society, vol. 35, no. 1, pp. 80-86, 2013.

[25] D. Wu, P. Lyu, L. Liang, F. Meng, and C. Yu, "Influences of slot width of stand-off layer on vibration property of slotted stand-off layer damping structure," Science Technology and Engineering, vol. 19, no. 15, pp. 7-11, 2019.

[26] B. Chen, S. He, and S. Li, "Optimization design of composite damping tile base on finite element analysis," Ship Science and Technology, vol. 37, no. 11, 2015.

[27] S. Yi, S. He, and J. Wang, "Study on vibration characteristics of unconstrained stand-off layer damping structure considering effect of adhesive layer," Fiber Reinforced Plastics/Composites, no. 8, pp. 42-47, 2017.

[28] H. Gorgani H, M. Adeli, and M. Hosseini, "Pull-in behavior of functionally graded micro/nano-beams for MEMS and NEMS switches," Microsystem Technologies, Composites Part B, no. 25, pp. 3165-3173, 2019.

[29] E. M. Miandoab, A. Yousefi-Koma, and H. N. Pishkenari, "Nonlocal and strain gradient based model for electrostatically actuated silicon nano-beams," Microsystem Technologies, vol. 21, no. 2, pp. 457-464, 2015.

[30] M. Abderrahmane, K. Abdelhakim, B. Abdelmoumen Anis et al., "A four-unknown refined plate theory for dynamic analysis of FG-sandwich plates under various boundary conditions," Steel and Composite Structure, vol. 36, no. 3, pp. 355-367, 2020.

[31] R. Mohamed, B. Kouider Halim, K. Abdelhakim et al., "A new innovative 3-unknowns HSDT for buckling and free vibration of exponentially graded sandwich plates resting on elastic foundations under various boundary conditions," Geomechanics and Engineering, vol. 22, no. 2, pp. 119-132, 2020.

[32] B. Fouad, B. Abdelmoumen Anis, T. Abdeldjebbar et al., "Stability and dynamic analyses of SW-CNT reinforced concrete beam resting on elastic-foundation," Computers and Concrete, vol. 25, no. 6, pp. 485-496, 2020.

[33] M. Hakima, B. Abdelmoumen Anis, H. Houari et al., "Investigation on hygro-thermal vibration of P-FG and symmetric S-FG nanobeam using integral Timoshenko beam theory," Advances in Nano Research, vol. 8, no. 4, pp. 293-305, 2020.

[34] R. Mohamed, K. Abdelhakim, B. Abdelmoumen Anis et al., "Influence of boundary conditions on the bending and free vibration behavior of FGM sandwich plates using a fourunknown refined integral plate theory," Computers and Concrete, vol. 25, no. 3, pp. 255-244, 2020.

[35] B. Abdelmoumen Anis, B. Fouad, S. R. Mahmoud, and A. Tounsi, "Buckling and dynamic behavior of the simply supported CNT-RC beams using an integral-first shear deformation theory," Computers and Concrete, vol. 25, no. 2, pp. 155-166, 2020.
[36] M. Hu, S. Yang, A. Wang, and H. Cheng, "Approximate analytical solutions for transient response of unconstrained damped cantilever beam considering shear deformation," Journal of Ship Mechanics, vol. 16, no. 7, pp. 812-819, 2012.

[37] D. Dai, Vibration and Noise Reduction Technology, Xi'an Jiaotong University Press, Xi'an, China, 1986. 